\title{
Market Research on the Ephedra Resource \\ in Xinjiang and its Development Trend
}

\author{
Yundong Liu \\ College of Life Science, Shihezi University \\ Shihezi, Xinjiang 832003, China \\ Tel: 86-993-205-7216 E-mail: liuyundongmail@163.com \\ Shaoming Wang \\ College of Life Science, Shihezi University \\ Shihezi, Xinjiang 832003, China \\ Tel: 86-993-205-7216Ｅ-mail: westwild@shzu.edu.cn
}

\begin{abstract}
Basing on referring to the literature about the usage of ephedra resource in Xinjiang, using the methods of personal investigation, telephone interview and E-mail, market research on the ephedra resource in Xinjiang was carried out in relevant governmental department, enterprises, scientific research institute, ephedra planter and those who reap ephedra. The formation and development of ephedra resource market in Xinjiang and the products were analyzed. In accordance with the status quo and future of ephedra market in Xinjiang, countermeasures were put forward to make full use of ephedra resource in the aspects of enterprise production, combination of traditional Chinese medicine and ecological environment protection.
\end{abstract}

Keywords: Ephedra resource, Xinjiang, Market consumption, Ephedrine

\section{Introduction}

Ephedra, which belongs to Gymnospermae, Ephedraceae, is an ancient genus (Liu, 2000). There are about 67 species, 40 of which are found in old continent, and 27 of which are found in new continent (14 are in North America, 13 are in South America). There are 15 species in China, two varietas and one forma, and there are 10 species, one forma in Xinjiang, which account for $66 \%$ of the total ephedra resources in China (Shen, 1995). Chinese Pharmacopoeia (2005 edition) adopted 3 species: E.sinica Stapf., E.intermedia Schrenk et Mey. and E.equisetina Bunge ( State Pharmacopeia Committee of China, 2005).

Ephedra is used as an important traditional Chinese medicine since its medicinal value was found. In Shennong's Classic of Materia Medica, Ephedra was used in ventilating lung, diaphoresis, pungent warm and relieving rheumatic pains. Ephedra is a precious medicinal plant in China, it was recorded in all the medical books in the past dynasties (The Editorial Committee of The Plant Index of Xinjiang, 1994), and it is the only raw material to extract ephedrine. The ephedrine, naphtha, flavone and amylose of ephedra can be used as anti-asthmatics, and can raise pressure, shrink blood vessel and lower temperature. In 1885, a Japanese named Shanli extracted ephedrine from Ephedra sinica Stapf, after that, ephedra is mainly used to extract ephedrine. Ephedra is not only a medicinal plant, but also a middling grazing in winter and spring because it has large roots, can endure dry, cold and leanness, also, it is a good windbreak and sand-fixer (Jiang and Sun, 2001).

In recent years, the values of ephedra are gradually found, and ephedra is greatly consumed in market. The exploitation of ephedra resources accelerated the economic development, but ephedra is a rare natural resource, over exploitation of ephedra, overgrazing and opening up wasteland led to the shrinking of ephedra distribution, reduction of output and quality decline. Accordingly, the ephedra market changes greatly, stockbreeding is affected to a certain extent, and the vulnerable desert ecological environment will get worse and worse (Zha, et al., 2002). This paper studied the market of medicinal ephedra in Xinjiang and analyzed its development trend, with the purpose of providing reference for the scientific management, protection and sustainable utilization of medicinal ephedra in Xinjiang, and for solving the contradiction between the sustainable utilization of natural resources and environmental protection. 


\section{The formation and development of ephedra market in Xinjiang}

\subsection{The geographical condition in Xinjiang and ephedra distribution}

Xinjiang is located in the northwest of China, it covers over 1.66 million square kilometers. Xinjiang is about $1 / 6$ of the total area of Chinese land, and is the largest province of China. Xinjiang is located in the inner side of Asia, its landform is complex, the climate in Xinjiang is typical continental climate because it is away from the ocean, and is influenced by the closed landform and atmospheric circulation factors. Xinjiang is located at the connective site of several large geographical units, such as Altai, Tianshan Mountain, Pamirs, Kunlun Mountain, Aerjin Mountain and North Tibet Altiplano. Also, it is located at the connection site of European-Asian forest subregion, European-Asian grassland, central Asia desert, the desert subregion in the central Asia and the Himalayan plant subregion (Institute of Botany, CAS and Team of Xinjiang Comprehensive Scientific Survey, CAS, 1978). Owing to the complex and versatile natural environment, ephedra resources in Xinjiang are abundant, there are multiple species and the output is of large potential, ephedra spread over champaign, hills, Tulufan Basin that is 154 meters above the sea level, and the valley of mountain that is 4000 meters above the sea level (Liu, 1991).

\subsection{The utilization of ephedra resources in Xinjiang and the formation of ephedra market}

The pollens of ephedra were present in various stratums in the Cretaceous period, and in Oligocene period, it spread over all the stratums. The form of ephedra didn't change much since then, so it is an ancient plant (Yang, 2002). Ephedra spreads widely in Xinjiang, before it was used in industry to extract ephedrine, nobody paid attention to the plant, it was rarely used as a resource but used as fuel, some were used as pasture in spring and autumn, only a little was used as traditional Chinese medicine, hence, at that time, the amount of ephedra used in medicine is stable.

In 1930s, Chinese scholars firstly extracted a pure biotin from ephedra, i.e. ephedrine. It is indicated that ephedrine has two optical isomers, the levorotatory one is the well known ephedrine, and the dextrorotatory one is pseudo-ephedrine. The discovery greatly affected the international pharmacy world, after that, ephedrine was taken as a kind of "adrenomimetics" and was recorded by pharmacopoeia of European and American countries (Jiang and Sun, 2001).

Since 1950s, ephedrine production in China increased steadily; ephedrine was mainly manufactured as preparation. The rapid growth of international demand on ephedrine led to the great increase of ephedrine production in China. In 1960s, Xinjiang Pharmaceutical Factory was the first one to produce ephedrine, and in 1990s, there were 8 enterprises that produced ephedrine, the annual output was 200-250 tons, which accounted for $60 \%$ of the national output of ephedrine. The wild ephedra, the raw material, was not destroyed from 1960s to 1980s. The third statistical investigation into the Chinese traditional medicine resources in 1980s showed that the ephedra resources in Xinjiang was 540 thousand tons, Xinjiang Heshuo Ephedrine Products Co. Ltd, which was the largest company, can produce 180 tons of ephedrine annually, others can produce 10 tons to 80 tons. In late 1970s, the price of exported ephedrine was 110 thousand Yuan per ton, after ephedrine was found to play a role in losing weight, the supply of ephedrine in international market became short, and the price rushed to 550 thousand Yuan per ton, which is five times of the price in 1970s (Jia, 1997), Investigation showed that the highest price of ephedrine was over 60 thousand Yuan per ton. Enterprises' planned demand on ephedra exceeded the largest ephedra output in Xinjiang, most enterprises fell short of ephedra resource, so they raised the price to get enough raw material. Most ephedra diggers know little about the characteristic of ephedra, they dig ephedra regardless of season and manner, and some even uproot the ephedrine in order to be faster than others and to hold ephedra resources. The area, amount and the quality of ephedra are decreasing, and the vegetation and ecological environment of the desert area are destroyed. Once the ephedra is destroyed, it will be difficult to be restored. China has put forward several regulations to protect ephedra resources, such as Regulations on the Prohibition of the Collection and Selling of Hairy Grass and Unregulated Collection of Liquorice Roots and Chinese Ephedra (No.13 (2000) of State Council) (Liu, 2004; He, 2002). Table 1 and table 2 shows the enterprises that produce ephedrine and the enterprises that export ephedrine and it analogues in Xinjiang respectively.

Since 1990s, ephedra is cultivated by human in some districts of Xinjiang, such as Mulei, Hutubi, Ataile, Wenquan and Shuodu, sometimes total cultivated ephedra is up to 2000 hektares.

\section{Changes in ephedra resource market in Xinjiang and analysis of the ephedrine export}

Ephedrine from Xinjiang is for both domestic market and international market, and all of the ephedrine analogues (Ephedrine extract powder, pseudo-ephedrine) are exported. The products of ephedrine producing enterprises in China are crude extracts; they have low-level technology and small added value. In Martindale, the Complete Drug Reference, at least 360 kinds of preparations that contain ephedrine are recorded. In China, over 90 kinds of medicine contain ephedrine, such as Compound Pseudo-ephedrine Hydrochloride Tablets, Composite Terfenadine Tablets. In China, products from different enterprises are similar to one another, and there is great dependence on foreign market. The United States, the largest customer of Chinese ephedrine, greatly reduced the amount of ephedrine from China, artificial ephedrine is growing up, and the technology is improving day by day, so the demand of international market on ephedrine will grow steadily, the great demand on ephedrine caused by "food for losing weight" in 1990s will never 
come up.

Since 2000, the demand of international market on ephedrine is always about 2000 tons, the ephedrine from Xinjiang accounts for $1 / 4$ of the total natural ephedrine in international market. The Food and Drug Administration (FDA) of the United States demanded that ephedrine would be forbidden to be added in food for losing weight from April, 2004. In 2004, China became the third largest country that produce and export ephedrine, following Germany and Indian. Chifeng Pharmacy Group of Inner Mongolia and Kangyu Pharmacy Group of Zhejiang have become the largest domestic ephedrine producing enterprises. Ephedrine export in Xinjiang almost came to a halt in 2003. The export situation of pseudo-ephedrine in recent years would indicate the dynamic variation of ephedra product in Xinjiang as shown in figure 1, it can be seen that there was great annual variation in the export of pseudo-ephedrine, the largest amount was 134 thousand $\mathrm{kg}$ in 2001, and the smallest amount was 11.075 thousand $\mathrm{kg}$ in 2006, generally, the amount of exported ephedrine is decreasing, and it depends on international market to a great extent.

\section{The development trend of ephedra market in Xinjiang and countermeasure}

Artificial synthesized ephedrine is of good quality and costs less than extracted natural ephedrine, in addition, the output of synthesized ephedrine is stable. The international demand on ephedrine decreased greatly, FDA of the United States decided to eliminate ephedrine from the list of "dietary supplement". Ephedrine, morphine and heroin have similar effect, they are raw materials for both medicine and drugs, ephedrine can be manufactured as the famous "ice drug" (Methamphetamine), ecstasy, and so on. So ephedrine is one of the rigidly controlled raw materials for medicine by International Organization against Drug Abuse, Chinese government has established several measures to control the ephedrine product, enterprises are facing up to great challenges in the inspection for environment protection, and they should manage the enterprise scientifically and improve the quality of employees.

The challenges mentioned above demand reform in the enterprises that produce ephedrine. Market competition and governmental guidance will be introduced to cultivate one or two standardized enterprises that will have scientific management, apply high-new technology, produce high-quality product, and improve the added value of product, so the enterprise can base itself upon Xinjiang and meet the need of domestic and international market. The advantage of resource and brand should be brought into play thoroughly, so as to ensure the market share of Xinjiang's ephedrine in domestic and international natural ephedrine product market.

Over digging led to the sharp decrease of wild ephedra in Xinjiang, and led to the deterioration of the vulnerable ecological environment and desertification of farmland soil. The wild ephedra resource suffered the greatest destroy since 1900. Governmental departments (Department of Animal Husbandry, Department of Forestry, Drug Supervision and Management Department, Department of Agriculture) of Xinjiang Uygur Autonomous Region and Xinjiang Production and Construction Corps should make a thorough investigation into the wild ephedra resources, and divide the ephedra area into different kinds, including area that is forbidden to be exploited, area that can be exploited by turns, and areas that should be protected. In that way, the destroyed wild ephedra will be restored, other vegetation will also be restored and the ecological environment will be protected.

The cultivation of ephedra had become a mature technology since 1990s; government will continuously support enterprises to establish their own raw material base, so as to ensure the stable and sufficient raw material supply.

In a word, after the formation, development and rational regression of Xinjiang ephedra market, ephedra producing enterprises, ephedra cultivating enterprise and individual as well as the government will be more rational in ephedra management. Ephedra in Xinjiang will mainly be used as raw materials and traditional Chinese medicine, and be used to protect ecological environment. The amount of ephedra that is used as raw material for ephedrine producing enterprise will be greatly reduced, so the ephedra resources will have an opportunity to be restored.

\section{Acknowledgement}

We would like to thank Urumchi Customs People's republic of China; Xinjiang Urumchi Municipality Food and Drug Administration; Xinjiang Foreign Economy Trade; Department of Animal Husbandry of Xinjiang Uygur Autonomous Region; Xinjiang Institute of Ecology and Geography, Chinese Academy of Sciences and Xinjiang International Industry Co. Ltd.

\section{References}

He, Baoyen. Si, Jianning and Zhang, Yongqing. (2002). Present Situation of Ephedra Resources and Their Exploiting Countermeasures. World Science and Technology-Modernization of Traditional Chinese Medicine. 4 (4): 63-68.

Institute of Botany, Chinese Academy of Sciences and Team of Xinjiang Comprehensive Scientific Survey, Chinese Academy of Sciences. (1978). The Vegetation and its Utilization in Xinjiang. [M]. Beijing: Science Press.

Jia, Xiaoguang and Sulaiman Halike. (1997). Utilization and protection of Chinese ephedra resources. International workshop about the energy consumption mode and the influence on environment [A]. 397-398. 
Jiang, Hailou and Sun, Shuangyin. (2001). Precious Vegetation Herba Ephedrae. Inner Mongolia:The Publishing House of Science Technology. 1-19.

Liu, Guojun. (2000). Ephedra [M]. Beijing: China Press of Traditional Chinese Medicine.

Liu, Guojun. (1991). Study on the conditions for ephedra in Xinjiang. Abstracts of fiftieth anniversary meeting of Botanical Society of Xinjiang. Beijing: Science press. 325-328.

Liu, Lei. Liu, Jianjun, Huang, Shaohua and Wang, Jun. (2004). Protection and Utilization of Ephedra resources in Xinjiang. Arid Environmental Monitoring. [J]. (18) 3: 146.

Shen, Guanmian. (1995). Distribution and evolution of the genus ephedra in china, Acta Botanica Yunnanica, [J] 17 (1):15-20.

State Pharmacopeia Committee of China. (2005). Chinese Pharmacopeia. [S]. Beijing: Chemical Industry Press. 233.

The Editorial Committee of The Plant Index of Xinjiang. (1994). The Plant Index of Xinjiang. Volum 1. [M] Urumchi: Xinjiang Science, Technology and Sanitation Publishing House. (K). 87-88

Yang, Yong. (2002). Classification of Ephedraceae in China and differentiation of Ephedraceae. (D). Doctor Dissertations of Institute of Botany, Chinese Academy of Sciences. 92-121.

Zha, Lihang. Su, Zhiguo and Zhang, Guozheng. (2002). Application and research on ephedra resource. Chinese Bulletin of Botany. [J] 19 (4): 396-405.

Table 1. Enterprises that produce ephedrine and other ephedrine analogues in Xinjiang (2007)

\begin{tabular}{|c|c|}
\hline Enterprises & Main products \\
\hline Xinjiang Pharmaceutical Factory & $\begin{array}{l}\text { Ephedrine, Pseudo-ephedrine, Ephedrine extract } \\
\text { powder }\end{array}$ \\
\hline $\begin{array}{l}\text { Xinjiang Tuokexun County Tianshan Mountain } \\
\text { Joint Ephedrine Factory }\end{array}$ & Ephedrine, Pseudo-ephedrine \\
\hline Xinjiang Heshuo Ephedrine Products Co.Ltd & $\begin{array}{l}\text { Ephedrine, Pseudo-ephedrine, Ephedrine extract } \\
\text { powder }\end{array}$ \\
\hline Xinjiang Hamigequan Pharmaceutical Co., Ltd. & Ephedrine, Pseudo-ephedrine \\
\hline Xinjiang Tuofeng Pharmaceutical Co., Ltd. & Ephedrine, Pseudo-ephedrine \\
\hline Xinjiang Wenquan County Ephedrine Factory & $\begin{array}{l}\text { Ephedrine, Pseudo-ephedrine, Ephedrine extract } \\
\text { powder }\end{array}$ \\
\hline Xinjiang Kuche County Joint Ephedrine Factory & Ephedrine, Pseudo-ephedrine \\
\hline Xinjiang Ashan Pharmaceutical Co., Ltd. & $\begin{array}{l}\text { Ephedrine, Pseudo-ephedrine, Ephedrine extract } \\
\text { powder }\end{array}$ \\
\hline
\end{tabular}

Table 2. Enterprises that export ephedrine and other ephedrine analogues in Xinjiang (2007)

\begin{tabular}{|c|c|}
\hline Enterprises that export ephedrine & Enterprise that export ephedrine analogues \\
\hline $\begin{array}{l}\text { Xinjiang Medicines and Health Products Import } \\
\text { \& Export Corp. }\end{array}$ & $\begin{array}{l}\text { Xinjiang Medicines and Health Products Import } \\
\& \text { Export Corp. }\end{array}$ \\
\hline $\begin{array}{l}\text { Xinjiang Machinery, Chemicals, Metals \& } \\
\text { Minerals, Light Industry Product Import. \& } \\
\text { Export. Corp. }\end{array}$ & $\begin{array}{l}\text { Xinjiang Machinery, Chemicals, Metals \& } \\
\text { Minerals, Light Industry Product Import. \& } \\
\text { Export. Corp. }\end{array}$ \\
\hline $\begin{array}{l}\text { Xinjiang (Production and Construction Corps) } \\
\text { Nongken Foreign Economic \& Trade Industry } \\
\text { Development Corp. }\end{array}$ & $\begin{array}{l}\text { Xinjiang (Production and Construction Corps) } \\
\text { Nongken Foreign Economic \& Trade Industry } \\
\text { Development Corp. }\end{array}$ \\
\hline \multicolumn{2}{|l|}{ Xinjiang Heshuo Ephedrine Products Co.Ltd } \\
\hline \multicolumn{2}{|l|}{ Xinjiang Pharmaceutical Factory } \\
\hline Xinjiang Wenquan County Ephedrine Factory & \\
\hline
\end{tabular}




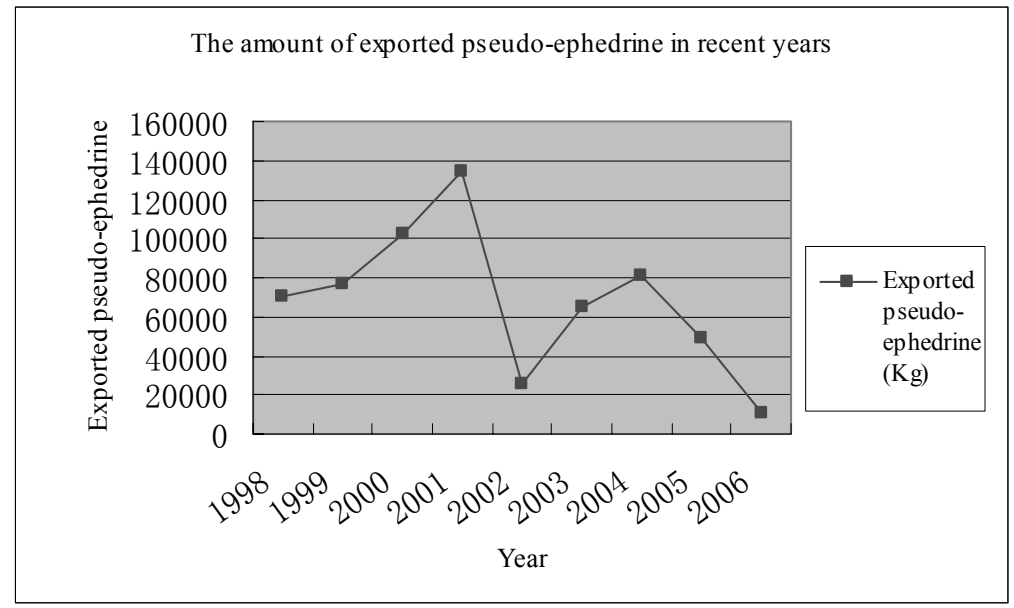

Figure 1. The annual amount of exported pseudo-ephedrine in recent years 